\title{
PREVALENCE OF ROOT FILLED TEETH IN AN ADULT POPULATION (LVIV, UKRAINE) FOUND ON DIGITAL PANORAMIC RADIOGRAPHS
}

DOI: 10.36740/WLek202004112

\author{
Nataliya Dydyk', Olha Hrynyshyn² \\ 'DEPARTMENT OF PROSTHETIC DENTISTRY, DANYLO HALYTSKY LVIV NATIONAL MEDICAL UNIVERSITY, LVIV, UKRAINE \\ 2DEPARTMENT OF PEDIATRIC DENTISTRY, DANYLO HALYTSKY LVIV NATIONAL MEDICAL UNIVERSITY, LVIV, UKRAINE
}

\begin{abstract}
The aim of this study was to determine the frequency of endodontic treatment in an adult Ukrainian population in relation to the age and its distribution depending on the type of the teeth.

Materials and methods: A total of 435 digital panoramic radiographs of adults (aged 18 to 72 years) were examined. A tooth was qualified as root filled (endodontically treated), if radiopaque root-filling material was determined in the pulp chamber and/or in the root canals. Pearson's chi-squared test ( $X^{2}$ ) and Spearman's rank correlation were applied for data analysis.

Results: It was revealed that $82.5 \%$ of patients had previously received endodontic treatment of the teeth. The overall percentage of root filled teeth in adult dentition is $12.08 \%$. The analysis of the rate of endodontically treated teeth in different age groups identified an increasing of treated teeth with age - from $5.2 \%$ in the youngest cohort (18-19 years old) to $24.9 \%$ in the oldest cohorts. It was revealed that 822 teeth (14.2\%) on maxilla and $569(9.9 \%)$ on the mandible were endodontically treated. Most often root filled teeth were first mandibular molars (39.3\%), first maxillary molars (26.7\%) and second maxillary premolars (20.4\%). Much lower rate of endodontic treatment were considered in lower mandibular incisors and canines $(0.7 \%, 0.9 \%$ and $1.5 \%$ respectively).

Conclusions: A total of $82.5 \%$ examined adults had one or more endodontically treated teeth in this study. The obtained results prove the necessity of prevention of caries with special emphasis on the first maxillary and mandibular molars, and maxillary second premolars, which have significantly higher frequency of root canal treatment in comparison to other teeth groups.
\end{abstract}

KEY WORDS: endodontic treatment, root filled teeth, prevalence, adult population

Wiad Lek. 2020;73(4):691-695

\section{INTRODUCTION}

Integrity of dentition contributes significantly to the quality of human life thus retention of natural teeth for a lifetime is a global priority of medicine in general and a primary goal of dentistry in particular $[1,2,3]$. Endodontic status is a crucial characteristic of adults dentition $[4,5]$ which results from the efficacy of preventive strategies for caries and its complications and is a strict predictor of future teeth loss. Numerous studies show that root filled teeth are more frequently associated with periapical pathology [6,7]; significant loss of the hard tooth tissue $[8,9]$, are predisposed to cracks and fractures $[10,11]$ and need extensive restorations $[12,13]$ than vital teeth.

In last decades clinical researches confirmed that positive outcome of root canal treatment exceeded $90 \%$ of cases $[14,15,16]$ if performed by experienced endodontists in a appropriately equipped offices in strict compliance with the academic guidelines. However, cross-sectional studies of population in many countries highlighted a much lower percentage of long-term outcomes of endodontic treatment performed by general dentists - from $35.5 \%$ to $81 \%$ $[17,18,19]$. Therefore, the quality of endodontic treatment and stability of its positive effect without the need of teeth retreatment or extraction are of immense importance worldwide [20,21]. Similar studies have been carried out earlier in Ukraine [22]. The panoramic radiographs of a large cohort of adult patients revealed that over $80 \%$ of adults had endodontically treated teeth, $12 \%$ of the teeth were endodontically treated, $41.6 \%$ of treated teeth were classified as those with apical periodontitis. However, the scientific literature published in English lacks current data on the status of the issue of endodontic treatment in Ukraine, its frequency and distribution.

\section{THE AIM}

The aim of this study was to establish the prevalence of root canal treatment in an adult Ukrainian population in relation to the age and its frequency depending on the type of the teeth.

\section{MATERIALS AND METHODS}

The 435 adults aged 18 to 72 , who visited the dental clinic in 2017 with examination purpose for the first time and had not had an endodontic treatment at least 12 months before visit were included in the investigation. Excluding criteria were as following: 1) patients with emergency 


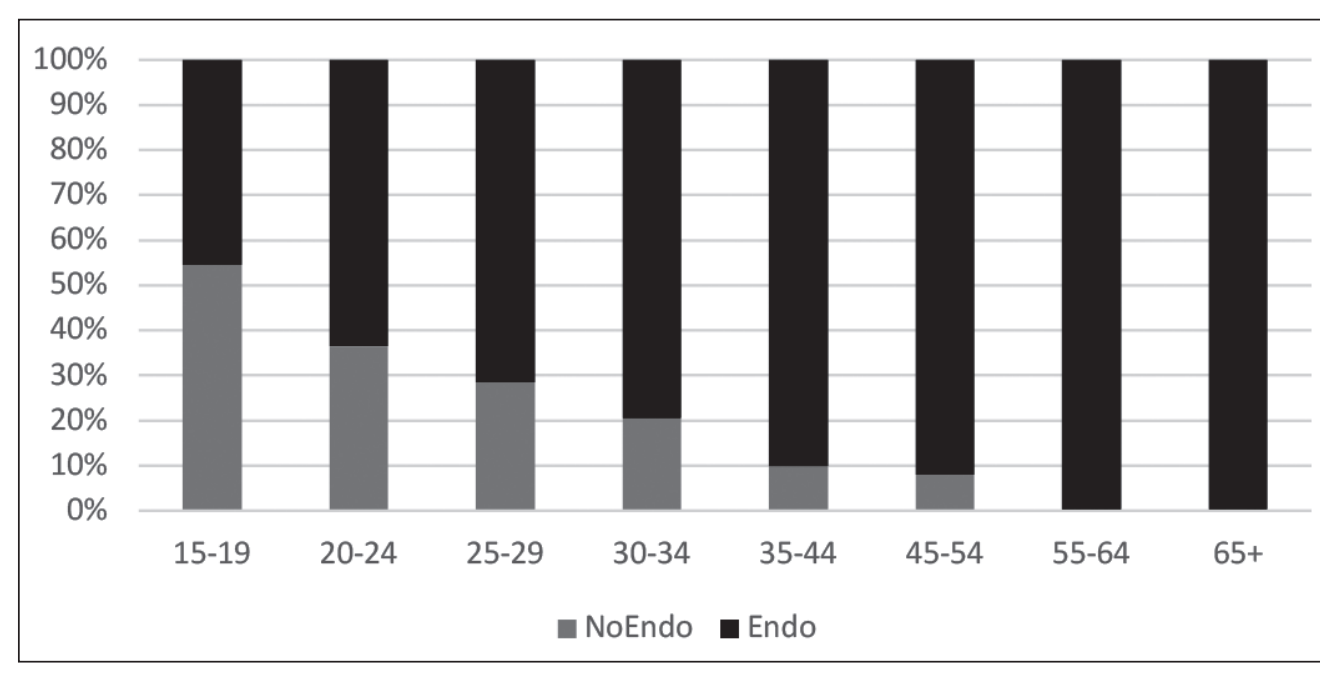

Fig.1. Age distribution of the patients with endodontically treated teeth dental treatment needs due to caries complications; 2) patients with severe degree of periodontitis; 3 ) completely edentulous patients. The study was approved by the Bioethics Committee of Danylo Halytsky Lviv National Medical University.

A total of 435 digital panoramic radiographs was examined. The radiographs were taken on a Gendex machine GXDP-700-1 (Finland). The teeth were recorded according to the FDI nomenclature using two-digit numbers, the first digit identifying the tooth location in a sector of the permanent dentition and the second one indicating the location of the tooth from the midline. The third molars $(18,28,38,48)$ were excluded. For a comparative analysis of the results, the examined teeth were divided into groups according to their location in the upper or lower jaw, on the basis of their anatomy - into anatomic pairs of structurally identical, symmetrically located teeth (for instance, 11-21, 36-46, etc.). A tooth was qualified as root filled, if the radiograph revealed radiopaque root-filling material in the pulp chamber and/or in the root canals.

In order to estimate the statistical significance of the difference of a characteristic or an index distribution between two or more groups, contingency tables and Pearson's chi-squared test $\left(\chi^{2}\right)$ were used. To evaluate the magnitude of the difference, when estimating the statistical significance, the measure of the effect size Cohen's w was used. Spearman's rank correlation coefficient was used to establish the correlations. Statistical analysis was performed in RStudio v.1.1.442 and R Commander v.2.4-4. The statistical power and sample size were calculated using G Power v.3.1.9.2. For processing the primary data and building results spreadsheets, Microsoft Excel 2016 was used.The statistical significance was estimated for $\mathrm{p}<0.05$; the desired power used for calculating the required sample size was established at 0.8 .

\section{RESULTS}

Analysis of the age and gender distribution of the sample population and analysis of the age distribution of the sample population with endodontically treated teeth.
Table 1. Frequency of root filled teeth in dentitions of examined age groups.

\begin{tabular}{|c|c|c|c|}
\hline \multirow[t]{2}{*}{ Age group } & \multirow{2}{*}{$\begin{array}{l}\text { Teeth } \\
(100 \%)\end{array}$} & \multicolumn{2}{|c|}{$\begin{array}{c}\text { Root canal filled } \\
\text { teeth }\end{array}$} \\
\hline & & number & $\%$ \\
\hline under 19 & 307 & 16 & 5.2 \\
\hline $20-24$ & 1441 & 64 & 4.4 \\
\hline $25-29$ & 1732 & 135 & 7.8 \\
\hline $30-34$ & 2120 & 165 & 7.8 \\
\hline $35-44$ & 3276 & 469 & 14.3 \\
\hline $45-54$ & 1571 & 277 & 17.6 \\
\hline $55-64$ & 784 & 195 & 24.9 \\
\hline $65+$ & 281 & 70 & 24.9 \\
\hline Total & 11512 & 1391 & 12.1 \\
\hline
\end{tabular}

The sample included 435 patients: 196 (45.06\%) males and 239 (54.94\%) females. The most representative group of patients was aged 35-44 (28.28\%).

Most part (82.5\%) of examined patients had received endodontic treatment before. The analysis of the age distribution of the patients with root filled teeth revealed a clear tendency towards the increase in the proportion of patients with root filled teeth from $45.5 \%$ in those aged under 19 to $100 \%$ in the 55 -64-year-olds ( $\mathrm{p}<0.0001$ for $\chi^{2}$ $=48.10$ and $\mathrm{df}=7$ ) (fig. 1 ).

Analysis of the frequency of endodontically treated teeth in patients from different age groups.

Overall, $12,08 \%$ of the examined patients had root canal filled teeth in their oral cavity. A tendency towards the increase of number of root canal filled teeth with age is evident - the older the patient is, the more root filled teeth he/she has (Table 1). The significance of the difference between the age groups was confirmed using the contingency tables and Pearson's chi-squared test $(\mathrm{p}<0.0001$ for $\chi^{2}=384$ and $\left.\mathrm{df}=7\right)$.

Analysis of the endodontic treatment frequency for the maxillary and mandibular teeth. 
Table 2. Frequency of endodontic treatment of the upper and lower permanent teeth

\begin{tabular}{|c|c|c|c|c|c|c|}
\hline \multirow{3}{*}{ Anatomical pair } & \multicolumn{3}{|c|}{ Upper jaw } & \multicolumn{3}{|c|}{ Lower jaw } \\
\hline & \multirow{2}{*}{$\begin{array}{l}\text { Examined teeth } \\
(100 \%)\end{array}$} & \multicolumn{2}{|c|}{ Root filled teeth } & \multirow{2}{*}{$\begin{array}{l}\text { Examined teeth } \\
(100 \%)\end{array}$} & \multicolumn{2}{|c|}{ Root filled teeth } \\
\hline & & number & $\%$ & & number & $\%$ \\
\hline 1 & 858 & 116 & 13,5 & 864 & 6 & 0,7 \\
\hline 2 & 848 & 72 & 8,5 & 867 & 8 & 0,9 \\
\hline 3 & 861 & 52 & 6,0 & 868 & 13 & 1,5 \\
\hline 4 & 816 & 106 & 13,0 & 860 & 38 & 4,4 \\
\hline 5 & 790 & 161 & 20,4 & 819 & 123 & 15,0 \\
\hline 6 & 774 & 207 & 26,7 & 649 & 255 & 39,3 \\
\hline 7 & 840 & 108 & 12,9 & 798 & 126 & 15,8 \\
\hline Total & 5787 & 822 & 14,2 & 5725 & 569 & 9,9 \\
\hline
\end{tabular}

Table 3. Analysis of distribution of endodontic treatment of teeth of upper and lower jaws

\begin{tabular}{|c|c|c|c|c|c|}
\hline Anatomical pair & $\begin{array}{c}\text { Upper jaw, } \\
\text { root filled teeth \% }\end{array}$ & $\begin{array}{c}\text { Lower jaw, } \\
\text { root filled teeth \% }\end{array}$ & Difference \% & $\mathbf{P}$ & $\mathbf{w}$ \\
\hline 1 & $13.52 \%$ & $0.69 \%$ & $12.83 \%$ & $\mathrm{p}<0,0001$ & 0.25 \\
\hline 2 & $8.49 \%$ & $0.92 \%$ & $7.57 \%$ & $\mathrm{p}<0,0001$ & 0.18 \\
\hline 3 & $6.04 \%$ & $1.50 \%$ & $4.54 \%$ & $\mathrm{p}<0,0001$ & 0.12 \\
\hline 4 & $12.99 \%$ & $4.42 \%$ & $8.57 \%$ & $p<0,0001$ & 0.15 \\
\hline 5 & $20.38 \%$ & $15.02 \%$ & $5.36 \%$ & $p=0,005$ & 0.07 \\
\hline 6 & $26.74 \%$ & $39.29 \%$ & $-12.55 \%$ & $\mathrm{p}<0,0001$ & 0.13 \\
\hline 7 & $12.86 \%$ & $15.79 \%$ & $-2.93 \%$ & 0,09 & \\
\hline Total & $14.20 \%$ & $9.94 \%$ & $4.27 \%$ & $p<0,0001$ & 0.07 \\
\hline
\end{tabular}

A total of 5787 maxillary and 5725 mandibular teeth in 435 subjects were examined (Table 2). It was revealed that 822 teeth (14.2\%) on maxilla and 569 (9.9\%) on the mandible were root filled. The difference between the rates of endodontic treatment of maxillary and mandibular teeth was $4.3 \%$ and considered as statistically significant $\left(\mathrm{p}<0.0001\right.$ for $\chi^{2}=49$ and $\left.\mathrm{df}=1\right)$. The most frequently root filled maxillary teeth were the first molars and second premolars $-26.7 \%$ and 20.4 , respectively (Table 3 ). The lateral incisors and canines had signs of endodontic treatment the least frequently $-8.5 \%$ and $6.0 \%$, respectively. The difference between the numbers of treated maxillary and mandibular teeth was considered as statistically significant $\left(\mathrm{p}<0.0001\right.$ for $\chi^{2}=196$ and $\left.\mathrm{df}=6\right)$. First molars take a confident lead with regard to the number of endodontically treated teeth in mandible $-39.3 \%$. The lowest percentage of endodontically treated mandible teeth was found for central, lateral incisors and canines- $0.7 \%, 0.9 \%$ and $1.5 \%$, respectively. The difference between the numbers of treated maxillary and mandibular teeth was considered as statistically significant $\left(\mathrm{p}<0.0001\right.$ for $\chi^{2}=938$ and $\left.\mathrm{df}=6\right)$.

\section{DISCUSSION}

In this research, the frequency and distribution of endodontically treated teeth depending on the type of teeth, and patient's age were studied on digital OPGs. The sample group was formed of the patients who visited the dental clinic during 2017 for the first time, in order to acquire dental examination and treatment plan. All patients before that were treated at various dental institutions by different specialists. It is important to emphasize, that the radiographic examination had diagnostic value for the patients and, at the same time, they were additionally used for the scientific research. This approach is used by most scientists for similar researches [23,24].

In order to compare the obtained results with the studies carried out in other countries, one should consider the differences in the research design and sampling. For instance, a total of $82.5 \%$ examined adults had one or more endodontically treated teeth in this study. Fairly high prevalence rate was observed in group of 35-44-year-olds (90\%). In comparison, in Latvia and Lithuania, in the same age group, $87 \%$ of adults were subjected to endodontic treatment of teeth during lifetime period $[25,26]$ whereas in Oslo (Norway) only $23 \%$ of 35 -year-old adults underwent root canal treatment [27]. The same time, a strict correlation between age and proportion of adults with endodontically treated teeth was established in this study. Even in the youngest group (18-19-year-olds), $45.5 \%$ received endodontic treatment. Tolias et al. [28] studied the group of freshmen cadets aged 18-19 in two stages (1995-2001 and 2002-2008) and revealed a drop in the endodontic treatment prevalence from $20 \%$ to $13 \%$. The figures obtained 
in this study can be higher, first of all due to the specificity of sampling and the fact that even the youngest persons involved in the study had dental problems. Overall, the prevalence of endodontic treatment of $82.5 \%$ in Ukrainian adult population is higher than that in the West European countries, which may be a consequence of the higher caries prevalence rate and irregular dental check-ups.

The overall percentage of endodontically treated teeth in examined population appeared to be $12.08 \%$. The obtained resultr is lower in the range of the studies carried out in other countries For instance, Kabak and Abbot [29] (Belarus) reported 20\%, Sidaravicius et al (Lithuania) 15\%, Jersa and Kundzina (Latvia) 18\% of teeth with radiographic signs of endodontic treatment. Our results for endodontic treatment frequency find themselves in the range 1.55-26\% from the data published earlier.

The analysis of the number of endodontically treated teeth in different age groups revealed a pronounced tendency towards the increase of number of treated teeth with age - from $5.2 \%$ in the youngest cohorts (18-19 years old) to $24.9 \%$ in the oldest cohorts. The highest prevalence of endodontically treated teeth, according to the earlier published results, was found in Switzerland (26\%) [30], where the sample of population included patients aged 66. These outcomes coincide with our results obtained in the respective age group. Numerous studies confirm a gradual increase the prevalence of endodontic treatment and need for endodontic treatment with age caused by complications of caries, loose of crown restorations or injury. The same time, in Ukraine, the practice of pulpectomy prior to crown restorations or fixed partial dentures is still popular. As the population of Ukraine is getting older, following the global aging tendency, people expect to retain their natural teeth. Apparently, the prevalence of endodontic treatment in senior age cohorts will persist, which is why the importance of dental care to seniors should be considered when developing the university curricula.

Whereas the distribution of the examined maxillary and mandibular teeth were equal, the percentage of endodontically treated teeth was significantly higher for maxillary teeth (14\%), for the mandibular teeth, this index was significantly lower (10\%). Therefore, it can be stated that the maxillary teeth require an endodontic treatment more often .

In reverse order of frequency, most often endodontically treated teeth were first mandibular molars (39.3\%), first maxillary molars $(26.7 \%)$ and second maxillary premolars (20.4\%). Much lower rate of endodontic treatment were considered in lower mandibular incisors and canines $(0.7 \%, 0.9 \%$ and $1.5 \%$ respectively). The obtained results prove the necessity and importance of prevention of caries and its complications with special emphasis on the first maxillary and mandibular molars, and maxillary second premolars, which have significantly higher frequency of root canal treatment in comparison to other teeth groups. This suggests a high risk of caries in these teeth and proves the need for the development of the respective preventive strategies. Finally, the maxillary teeth are most frequently endodontically treated, which raises the issue of a differentiated approach and reassessment of the risk factors in the preventive strategy. Basic steps of preventive treatment for the young can have a tremendous impact in adult oral health. There is also a huge financial benefit from such a strategy.

\section{CONCLUSIONS}

A total of $82.5 \%$ examined adults had one or more endodontically treated teeth in this study. The obtained results prove the necessity of prevention of caries with special emphasis on the first maxillary and mandibular molars, and maxillary second premolars, which have significantly higher frequency of root canal treatment in comparison to other teeth groups.

\section{REFERENCES}

1. Liu P., McGrath C., Cheung G.S. Improvement in oral health-related quality of life after endodontic treatment: a prospective longitudinal study. J Endod. 2014 Jun;40(6):805-10.

2. Hamasha A.A., Hatiwsh A. Quality of life and satisfaction of patients after nonsurgical primary root canal treatment provided by undergraduate students, graduate students and endodontic specialists. Int Endod J. 2013 Dec;46(12):1131-9.

3. Visscher C.M., Lobbezoo F., Schuller A.A. Dental status and oral healthrelated quality of life. A population-based study. J Oral Rehabil. 2014 Jun;41(6):416-22.

4. Segura-Egea J.J., Martín-González J., Castellanos-Cosano L. Endodontic medicine: connections between apical periodontitis and systemic diseases. Int Endod J. 2015 0ct;48(10):933-51.

5. López-López J., Jané-Salas E., Estrugo-Devesa A., et al. Frequency and distribution of root-filled teeth and apical periodontitis in an adult population of Barcelona, Spain. Int Dent J. 2012 Feb;62(1):40-6.

6. Oztan M.D. Endodontic treatment of teeth associated with a large periapical lesion. Int Endod J. 2002 Jan;35(1):73-8.

7. García C.C., Sempere F.V., Diago M.P., et al. The post-endodontic periapical lesion: histologic and etiopathogenic aspects. Med Oral Patol Oral Cir Bucal. 2007 Dec 1;12(8):E585-90.

8. Dimitriu B., Vârlan C., Suciu I., et al. Current considerations concerning endodontically treated teeth: alteration of hard dental tissues and biomechanical properties following endodontic therapy. J Med Life. 2009 Jan-Mar;2(1):60-5.

9. Ikram 0.H., Patel S., Sauro S., et al. Micro-computed tomography of tooth tissue volume changes following endodontic procedures and post space preparation. Int Endod J. 2009 Dec;42(12):1071-6.

10. Seo D.G., YiY.A., Shin S.J., et al. Analysis of factors associated with cracked teeth. J Endod. 2012 Mar;38(3):288-92.

11. Khoshbin E., Donyavi Z., Abbasi Atibeh E., et al. The effect of canal preparation with four different rotary systems on formation of dentinal cracks: an in vitro evaluation. Iran Endod J. 2018 Spring;13(2):163-168.

12. Mannocci F., Cowie J. Restoration of endodontically treated teeth. $\mathrm{Br}$ Dent J. 2014 Mar;216(6):341-6.

13. Trushkowsky R.D. Esthetic and functional consideration in restoring endodontically treated teeth. Dent Clin North Am. 2011 Apr;55 (2):403-10.

14. Friedman S., Abitbol S., Lawrence H.P. Treatment outcome in endodontics: the Toronto Study. Phase 1: initial treatment. J Endod. 2003 Dec;29(12):787-93. 
15. Burry J.C., Stover S., Eichmiller F., et al. Outcomes of Primary Endodontic Therapy Provided by Endodontic Specialists Compared with Other Providers. J Endod. 2016 May;42(5):702-5.

16. Paredes-Vieyra J., Enriquez F.J. Success rate of single- versus two-visit root canal treatment of teeth with apical periodontitis: a randomized controlled trial. J Endod. 2012 Sep;38(9):1164-9.

17. Kielbassa A.M., Frank W., Madaus T. Radiologic assessment of quality of root canal fillings and periapical status in an Austrian subpopulation - An observational study. PLoS One. 2017 May 2;12(5):e0176724.

18. Song M., Park M., Lee C.Y., et al. Periapical status related to the quality of coronal restorations and root fillings in a Korean population. J Endod. 2014 Feb;40 (2):182-6.

19. Moreno J.0., Alves F.R., Gonçalves L.S., et al. Jr.Periradicular status and quality of root canal fillings and coronal restorations in an urban Colombian population. J Endod. 2013 May;39(5):600-4.

20. Lee A.H., Cheung G.S., Wong M.C. Long-term outcome of primary nonsurgical root canal treatment. Clin Oral Investig. 2012 Dec;16(6):160717.

21. Pirani C., Chersoni S., Montebugnoli L., Prati C. Long-term outcome of non-surgical root canal treatment: a retrospective analysis. Odontology. 2015 May;103(2):185-93.

22. Dydyk N.M. Periapical, endodontic, and prosthetic status of teeth in an adult Ukrainian population. Int Endod J.-2017. Vol.50 (Suppl.1): 47-8.

23. Peters L.B., Lindeboom J.A., Elst M.E., et al. Prevalence of apical periodontitis relative to endodontic treatment in an adult Dutch population: a repeated cross-sectional study. Oral Surg Oral Med Oral Pathol Oral Radiol Endod. 2011 Apr;111(4):523-8.

24. Huumonen S., Suominen A.L., Vehkalahti M.M. Prevalence of apical periodontitis in root filled teeth: findings from a nationwide survey in Finland. Int Endod J.2017 Mar;50(3):229-236.

25. Sidaravicius B., Aleksejuniene J., Eriksen H.M. Endodontic treatment and prevalence of apical periodontitis in an adult population of Vilnius, Lithuania. Endod Dent Traumatol. 1999 0ct;15(5):210-5

26. Jersa I., Kundzina R. Periapical status and quality of root fillings in a selected adult Riga population. Stomatologija. 2013;15(3):73-7.

27. Skudutyte-Rysstad R., Eriksen H.M. Endodontic status amongst 35-yearold Oslo citizens and changes over a 30-year period. Int Endod J. 2006 Aug;39(8):637-42.
28. Tolias D., Koletsi K., Mamai-Homata E., et al. Apical periodontitis in association with the quality of root fillings and coronal restorations: a 14-year investigation in young Greek adults. Oral Health Prev Dent. 2012;10(3):297-303.

29. Kabak Y., Abbott P.V. Prevalence of apical periodontitis and the quality of endodontic treatment in an adult Belarusian population. Int Endod J. 2005 Apr;38(4):238-45.

30. Imfeld T.N. Prevalence and quality of endodontic treatment in an elderly urban population of Switzerland. J Endod. 1991 Dec;17(12):604-7.

\section{ORCID and contributionship:}

Nataliya Dydyk - 0000-0001-9070-130X ${ }^{A, B, C, D, F}$

Olha Hrynyshyn - 0000-0001-7573-8702 ${ }^{A, B, C, E}$

\section{Conflicts of interest:}

Authors declare no conflict of interest.

\section{CORRESPONDING AUTHOR Nataliya Dydyk \\ Department of Prosthetic Dentistry, Danylo Halytsky Lviv National Medical University, Lviv, Ukraine e-mail:ndydyk@gmail.com}

Received: 21.09.2019

Accepted: 19.02 .2020

A - Work concept and design, B - Data collection and analysis, C - Responsibility for statistical analysis, D-Writing the article, $\mathbf{E}$-Critical review, $\mathbf{F}$ - Final approval of the article 